\title{
Ongoingly redesigning metacognitive questionnaires helping trainees to self-evaluate their translating
}

Francesc Fernández and Marta Arumí Ribas

Universitat Pompeu Fabra, Barcelona, Spain/Universitat Autònoma de Barcelona, Spain

\section{Introduction}

Metacognitive reflection raising the students' strategic awareness is being given increasing importance in classsroom research into socially co-constructed, self-regulated learning. This reflection can be promoted through metacognitive questionnaires (MQs) enabling learners to verbalize such reflection and being progressively introduced in undergraduate foreign language teaching (Arumí and Cañada 2005), interpreter training (Arumí 2006) and translator training (Fernández and Zabalbeascoa 2012). Research into the use of MQs by students from different subjects seems, thus, sufficiently well established for researchers to start addressing the effectiveness of MQs, including the perceived adequacy of their questions and how to improve on them, where necessary.

The present study deals precisely with the redesign of post-translation MQs used by trainees to self-evaluate their translating, a function of strategic subcompetence for trainees (as distinguished by Fernández and Zabalbeascoa, forthcoming). Post-translation MQs were ongoingly redesigned as needed, on the basis of students' feedback and the teacher's perceptions, in the course of a pedagogical intervention intended to develop trainees' strategic subcompetence. Our study analyses why questions in the post-translation MQs did or did not need to be redesigned so as to become metacognitively more effective. The relevance of the resulting redesign procedures lies, in our opinion, in the fact that they may well be applied to subjects other than translator or interpreter training in which strategic awareness is instrumental.

\section{Conceptual framework}

Metacognition and strategic subcompetence for trainees

Metacognition, a concept coined by Flavell (1979), refers to the knowledge and regulation of one's cognitive activities. Hence the distinction between declarative metacognition, what learners can verbalize about their cognition (Pozo et al. 2001: 26), and procedural metacognition, the processes by which they can make this verbalization possible (ibid.), i.e., planning, monitoring and evaluating (see Wenden 1999: 437).

These three processes lie at the core of strategic subcompetence for translator trainees, a concept developed by Fernández and Zabalbeascoa (2012: 742) and applying to teaching in 
the early stages of translator training. This concept takes as a starting point the concept of strategic subcompetence as defined by PACTE in terms of professional translating.

According to PACTE, strategic subcompetence is the most relevant of all subcompetences which make up translation competence (PACTE 2008: 106). This is the mainly procedural expert knowledge system which is needed to translate and which comprises several interrelated subcompetences: bilingual, extra-linguistic and instrumental and strategic (ibid. 107).

The relevance of strategic subcompetence lies in the fact that "it creates links between the different subcompetences [of translation competence], as it controls the translation process" (ibid. 107). It is "procedural knowledge to guarantee the efficiency of the translation process" (ibid. 106) and is made up of the following functions:

to plan the process and carry out the translation project [...] to evaluate the process and the partial results obtained in relation to the final purpose, to activate the various subcompetences and compensate for any shortcomings and to identify translation problems and apply procedures to solve them (PACTE 2008: 107)

The functions of strategic subcompetence for trainees are the result of reconsidering the cited functions and of introducing new ones, so as to promote strategic awareness metacognitively. Strategic subcompetence for trainees comprises, therefore, the functions of planning, monitoring and self-evaluating, as well as the function of activating the various subcompetences.

The first three functions are successive stages of the trainees metacognitive reflection on their translating, which enable them to verbalise certain aspects of this reflection. Two of these aspects, identifying translation problems and justifying their solutions to these problems by referring to successful strategies, can be considered additional functions of strategic subcompetence for trainees. They apply mainly, though not exclusively, to the trainees' selfevaluating of their translating and prove strategically relevant, in that both raise the students' awareness of the decision-making process inherent to translating, a process of which they may not always be sufficiently aware.

The socially shared development of strategic subcompetence for trainees through metacognitive questionnaires

Strategic subcompetence for trainees is developed in a socially-shared way within a community of apprentices. The members of this community co-construct knowledge by using the scaffolding provided not only by the teacher, but also by their peers. By 'scaffolding' we understand the help "which will enable a learner to accomplish a task which he would not have been quite able to manage on his own" (Kiraly 2000: 46).

Trainees carry out collaboratively the authentic activities of professional translators, thereby acquiring socially-shared expertise, following a typical three-stage process. According to Anderson (1990: 258-260) this process starts when novices develop a declarative knowledge of 
the skill. They can then recognize and address deficits. Finally, these actions become increasingly automated, as a more procedural knowledge emerges.

The process leading trainees to expertise through the development of their strategic subcompetence can be encouraged by using MQs. These are mediation instruments that include a series of more or less open-ended questions (cf. Esteve \& Arumí 2006: 164) that mostly revolve around strategic subcompetence and that can raise trainees' strategic awareness, thereby nurturing incipient expertise.

MQs break the process by which trainees learn how to translate strategically into more easily manageable chunks. Students deal with the mental actions involved either individually or in groups, by writing down their answers in order to clarify their ideas and improve their reasoning. MQs can be used by students to plan, monitor or self-evaluate their translating, as well as to assess their own learning.

Following Arumí (2009: 156), we consider that MQs have two principal aims: to progressively transfer the control and consciousness of educational activities to the trainees and to promote in them intermental dialogue (in social exchange with others) and intramental dialogue (in their own minds) as established by Vygotsky (1978: 42).

The first aim involves incorporating MQs in task sequences, so as to allow for reflective learning based on relevant challenges promoting the acquisition of strategic subcompetence. This happens as students engage in a process leading them to cognitive emancipation and, thus, to increased self-regulated learning.

The second aim involves providing trainees with appropriate feedback according to their responses to the MQs, especially if these lead them to awareness of their strong and/or weak points. In turn, student feedback on the MQs can also enhance the process of knowledge coconstruction, by helping the teacher to (re)design them so as to meet the students' evolving needs.

\section{The study}

\section{Setting}

This study was conducted in a general German-Spanish translation course at the Universitat Pompeu Fabra, Barcelona, in the academic year 2007-2008. The course was made up of two parts, each one lasting ten weeks and consisting of three modules. In addition, the course included two weekly face-to-face sessions in workshop format, with an extra two hours' autonomous work per week outside the classroom.

The course was addressed to first-year students with no previous translator instruction and was regularly attended by 15 students (of 20 enrolled). Their level of German was rather heterogeneous, lying, as a rule, slightly below the level of the texts to be translated, which was A2/B1 (Common European Framework of Reference for Languages). 


\section{Pedagogical intervention}

The research was the result of a pedagogical intervention primarily aimed at promoting the trainees' strategic subcompetence, represented by the functions of planning and self- evaluating their translating, as well as their competence to self-evaluate their learning. This intervention involved the use in sequence of three types of MQs: pre-translation; post-translation; and endmodule.

Pre-translation MQs (see appendix) were given to students before each translation assignment to help them plan their translating before the source text was shown on the basis of the brief provided by the teacher. The questions, all open-ended, targeted pragmatic features of the source text and the prospective target text, as well as foreseeable translation problems and how they might be solved. They were answered in the group, with the teacher providing the necessary scaffolding, including additional information, to be read after class, on the most significant problems and their possible solutions.

Post-translation MQs, which aimed at helping students to self-evaluate their translating, were presented after each translation. They were made up of three types of question: 'yes-no', open-ended and 'yes-no' followed by open ended. These questions focused on how students had proceeded in translating a text, as well as on translation problems and justifying their solutions. They were answered by the students in writing out of class, before they had submitted the corresponding translation assignment to the teacher for correction. The teacher commented on the post-translation MQs, also in writing, before handing them back along with the corrected translations, which were then discussed in class.

End-module MQs (see appendix) were aimed at helping students to self-evaluate their learning at the end of each three-week module as mediated by pre- and post-translation MQs. They consisted of either open-ended questions or 'yes-no' questions followed by open-ended questions, on the usefulness of these two types of MQs and on how they might be improved for future editions. End-module MQs were worked on after all pre-translation MQs in the module had been dealt with and after all translations in the module had been submitted for correction along with their corresponding post-translation MQs. End-module MQs were answered in writing by the students and commented on likewise by the teacher before being handed back.

Data collection and corpus of the study

As the study deals with the redesigning of MQs in relation to the trainees' self-evaluation of their translating, only post-translation MQs were considered. More specifically, the study focuses only on those used in the second module of each of the two parts of the course, to be referred to henceforth as module 2 and module 5 . This is for two reasons.

Firstly, in these two modules post-translation MQs were more frequently used than in any other module, as the number of texts that they applied to was also higher. In module 1 , students translated none, owing to the introductory character of this module, and in modules 3,4 and 6 , they translated only one long text as a collaborative translation project. Students translated 
three short texts in module 2 and two in module 5, thereby answering an equal number of posttranslation MQs. The five texts translated in modules 2 and 5 were the registration conditions of a language course (text 1), the description of the school organising the course (text 2), a piece from a short autobiographical story (text 3), a piece from a text on German recent history (text 4), and a piece from the script of the German film "The Life of Others" (text 5). Secondly, these two modules lay sufficiently apart from each other to make possible a study on such redesigning from one part of the course to the other.

Thus, the data chosen for research were the students' answers to the following two types of MQs:

1. The post-translation MQs submitted in modules 2 and 5 (34 and 19 questionnaires in each case resulting in $53 \mathrm{MQs}$ altogether);

2. The end-module MQs submitted at the end of modules 2 and 5 (13 and 12 end-module MQs respectively, i.e., 25 altogether). In this case, only the questions on post-translation MQs were considered.

Data analysis

The data analysis was carried out regarding each student's answer as a unit of analysis, with each dealt with differently, depending on which of the three following question types it applied to:

1. In the case of 'yes-no' questions, we merely took into account the respective 'yes' and 'no' answers;

2. In the case of open-ended questions, we applied first a thematic analysis to identify all items. Then, we grouped thematically related items into categories by cross-examining the data following a recursive process of abstraction and generalization, "partly based on participants perspectives and partly based on our own interpretation" (Creswell 2001: 20). Finally, we labelled the common core of the trainees' answers. This was done through students' key-words, whenever possible, as illustrated by the answer category 'consulting parallel texts' applying to the question 'What recommendations would you give to a peer having to translate this source text or an instance of the textual genre that it belongs to?'. Other answer-categories, though, were labelled in terms more distantly echoing the essence of the students' answers, as illustrated by the answer-categories 'general style conventions' and 'using the conventional equivalent' related to the twofold question 'what translation problems do you think you have adequately solved and why?'.

3. In the case of 'yes-no' questions followed by an open-ended question, we successively applied the procedures described for each one of these two question types. 


\section{Research questions and research approach}

The study is guided by the following closely related research questions:

1. What are the causes explaining the perceived inadequacy of the questions in the posttranslation MQs for modules 2 and 5 that were submitted to ongoing redesign?;

2. What procedures applied to this redesign?;

3. What was the effect of this redesign on the students' self-evaluation of their translating?

The study follows the premises of qualitative research, in that "the researcher is an instrument of data collection who gathers words [...], analyzes them inductively [...] and describes a process" (Creswell 2001: 14). However, we prefer to call our approach 'interpretive', following Arumí (2006: 180), as our study does not exclude quantification and considers data on a quantitative basis.

We carried out a case-study of a group of students as they took part in the course described in 3.2. In so doing, we applied an ethnographic methodology. We consider it the natural methodology for interpreting educational reality, owing to its emphasis on: empirical data; different levels of meanings; and comprehension of a process. So as to ensure intersubjective plausibility, we used investigator triangulation.

Results and discussion

In presenting and discussing the results of the research, we will deal with the post-translation MQs for modules 2 and 5 separately. Each question in the post-translation MQs is presented in a separate table, with a modified version of a given question appearing after the question that it evolved from. Answer-categories are listed immediately below their corresponding question. Their frequency is expressed in percentages calculated for each text, so as to facilitate comparison.

Post-translation MQs for module 2

Table 1. Question 1 in the post-translation MQs for module 2

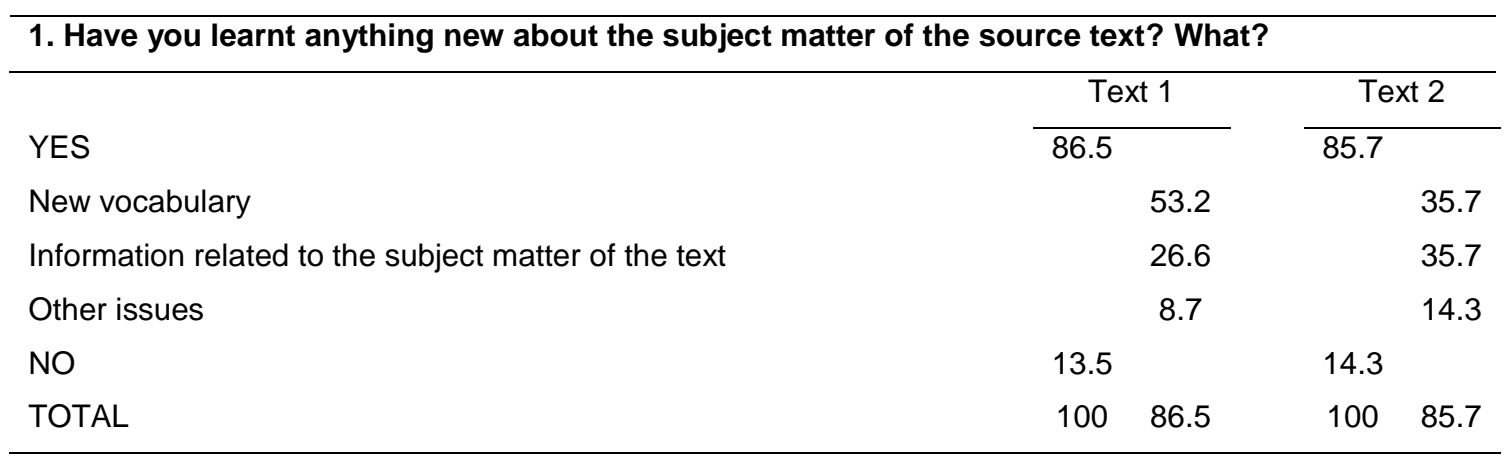




\begin{tabular}{lr}
\hline $\begin{array}{l}\text { 1. Have you learnt anything new about the German campaign against the Soviet Union? } \\
\text { If so, what? }\end{array}$ & Text 3 \\
\cline { 2 - 2 } YES & 71.4 \\
Information related to the German campaign against the Soviet Union & 50.1 \\
Other issues & 14.2 \\
New vocabulary & 7.1 \\
NO & 28.6 \\
TOTAL & 100 \\
\hline
\end{tabular}

Question 1 was made up of a 'yes-no' question followed by an open-ended question asking students if they had learnt something new about the subject matter of the source text and, if so, what. This twofold question assessed the application of the extra-linguistic subcompetence, "predominantly declarative knowledge [...] about the world in general and field specific." (PACTE 2008: 116).

In the post-translation $M Q$ for text 1 , the first part of question 1 was mostly answered with 'yes'. The most frequent answer to the second part of this question was, though, 'new vocabulary', which was twice as frequently referred to as information related to the subject matter of the text.

In the post-translation $M Q$ for text 2, the percentage of 'yes'-answers slightly fell in relation to the post-translation $M Q$ for text 1. Information to do with the subject matter of the text was, though, as frequently mentioned as 'new vocabulary', while 'other issues' was half as frequent as both.

Wishing to counteract such a decreasing trend and to raise the frequency of information related to the subject matter, the teacher decided to reword question 1, so that students could meet the aim missed previously, possibly owing to the too general wording of the question. Thus, in the post-translation MQ for text 3 the general term 'subject matter', as object of the mental action of the first part of question 1, was replaced by its specific manifestation in text 3 , 'the German campaign against the Soviet Union'.

Information related to this specific subject matter was significantly more frequently mentioned than information related to the general subject matter in the two previous texts. This happened to a greater extent from text 2 to text 3 than from text 1 to text 2 . This allows the statement that the modified version of question 1 more adequately targeted the intended aim, despite the percentage of 'yes' answers reaching its lowest level. 
Table 2. Question 2 in the post-translation MQs for module 2

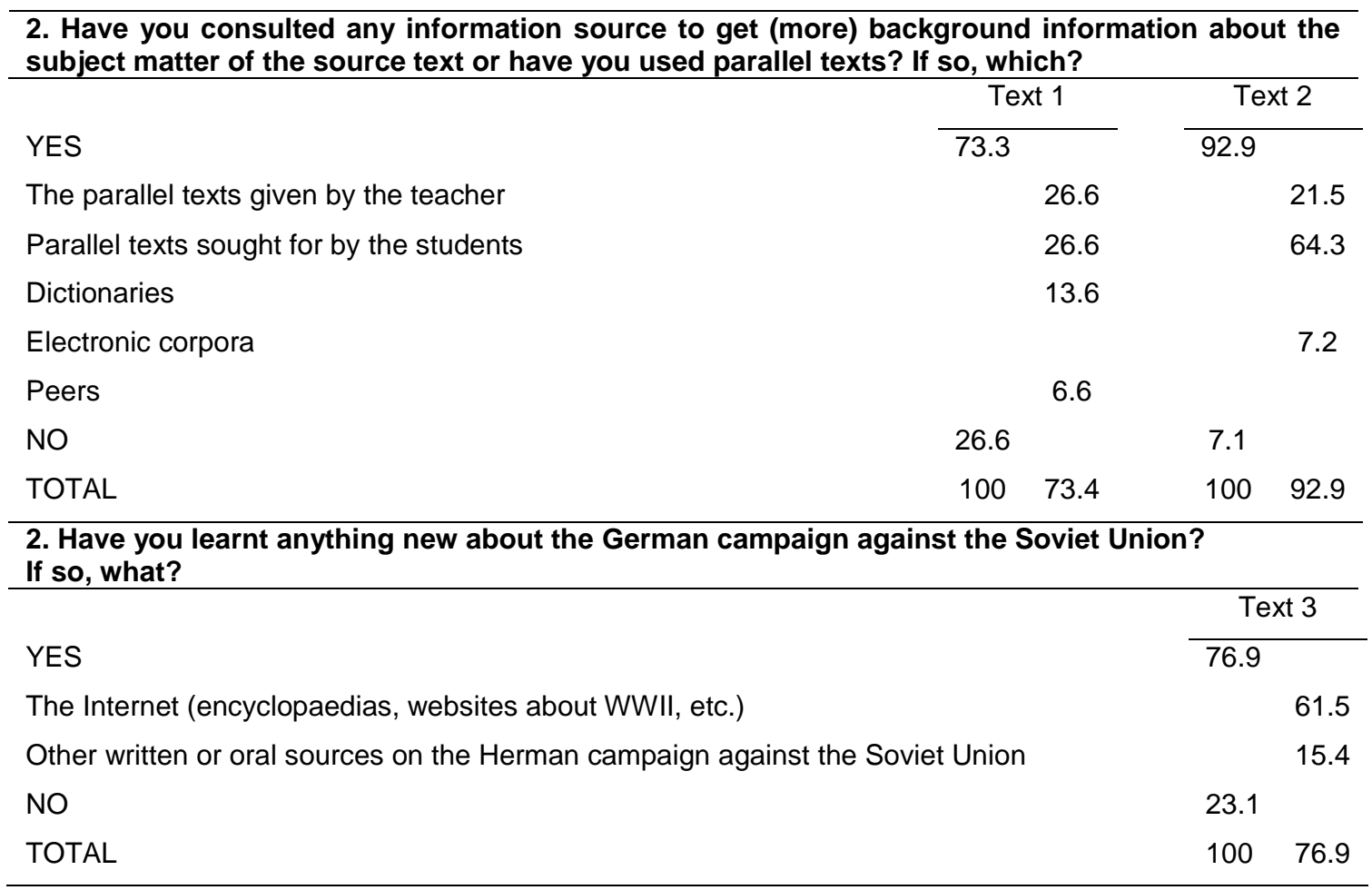

Question 2 was also made up of a 'yes-no' question followed by an open-ended question. It asked students if they had consulted any information source and, if so, which, thereby assessing the application of the instrumental subcompetence, "predominantly procedural knowledge related to the use of documentation resources and information and communication technologies applied to translation." (PACTE 2008: 106).

In the case of text 1 , such sources were resorted to with a considerable frequency, which became notably higher in the case of text 2 . 'Parallel texts given by the teacher' and 'parallel texts sought for by the students' were the two most frequent answer-categories in the posttranslation MQs for both texts. If considered together, these categories result in a frequency for parallel texts of $53.2 \%$ for text 1 and $85.8 \%$ for text 2 . Parallel texts were, thus, the information source most frequently consulted in translating the conventionalized textual genres of which both texts were instances.

Although such results conformed to the expected outcome, the teacher reworded question 2 in the post-translation $M Q$ for text 3 , to make it coherent both with the modified version of question 1 in this questionnaire and with the non-conventionalized character of text 3 . As a consequence, in the post-translation $\mathrm{MQ}$ for text 3 , the consultation of information sources was related to the subject matter of this text as redefined in question 2 , with parallel texts not being mentioned.

The most frequent answer-category was 'the Internet', followed at a considerable distance by 'other written or oral sources'. The percentage resulting from adding these two answercategories together, though, lies significantly below the percentage for parallel texts taken as a 
whole in the post-translation $M Q$ for text 2 , and only slightly above the percentage for parallel text taken as a whole in the post-translation $M Q$ for text 1 . Thus, it cannot be consistently stated that modifying question 2 involved a remarkable improvement in relation to its intended aim.

Table 3. Question 3 in the post-translation MQs for module 2

3. What problems do you think you have adequately solved and why?

\begin{tabular}{|c|c|c|c|c|c|c|}
\hline \multirow{2}{*}{$\begin{array}{c}\text { Problem-categories / } \\
\text { Justification-categories }\end{array}$} & \multicolumn{3}{|c|}{ Identification-frequency } & \multicolumn{3}{|c|}{ Justification-frequency } \\
\hline & T1 & T2 & T3 & $T 1$ & $T 2$ & T3 \\
\hline 1. General style conventions & 41.8 & 31.6 & 20 & 25 & 26.3 & 20 \\
\hline Using the conventional equivalent & & & & (25) & (26.3) & (10) \\
\hline 2. Genre-specific conventions & 25 & 41.9 & & 16.6 & 36.8 & \\
\hline Using the conventional equivalent & & & & (8.3) & (26.3) & \\
\hline 3.The author's personal style & & & 30 & & & 20 \\
\hline $\begin{array}{l}\text { Maintaining the sane style as the } \\
\text { source text }\end{array}$ & & & & & & (15) \\
\hline 4. Vocabulary & & 5.3 & 20 & & 5.3 & 5 \\
\hline Using the conventional equivalent & & & & & (5.3) & (5) \\
\hline 5. Cultural references & & & 15 & & & 10 \\
\hline $\begin{array}{l}\text { Adding explanations for the target } \\
\text { text-receiver }\end{array}$ & & & & & & (10) \\
\hline 6. Syntax & & 10.6 & & & 5.3 & \\
\hline $\begin{array}{l}\text { Thinking of previous solutions for the } \\
\text { same problem }\end{array}$ & & & & & (5.3) & \\
\hline 7. Text comprehension & & 5.3 & 5 & & & \\
\hline $\begin{array}{l}\text { 8. "Fulfilling the target text-receiver's } \\
\text { expectations" }\end{array}$ & 8.3 & 5.3 & & & & \\
\hline $\begin{array}{l}\text { 9. "Adding the grammatical subject in } \\
\text { Spanish" }\end{array}$ & & & 10 & & & 10 \\
\hline Solving grammatical ambiguity & & & & & & (10) \\
\hline $\begin{array}{l}\text { 10. "Adding information implicit in the } \\
\text { source text" }\end{array}$ & 8.3 & & & & & \\
\hline 11. "Avoiding literal translation" & 8.3 & & & & & \\
\hline 12. "Avoiding lexical repetition" & 8.3 & & & & & \\
\hline TOTAL/TOTAL & 100 & 100 & 100 & 41.6 & 73.7 & 65 \\
\hline
\end{tabular}

Question 3 consisted of a 'what' and 'why' part, addressing, respectively, the identification of translation problems adequately solved and the justification of their solutions.

As for the identification of translation problems, 12 categories of problems adequately solved emerged from the students' answers to the 'what' part of question 3, as shown in Table 3. More generalizable, strategically more relevant problems (problem-categories 1,2 and 5) ranked above less generalizable, strategically less relevant problems (problem-categories 3, 4, 6 and 7). In turn, both were more frequent than the remaining problem-categories, translation strategies quoted from the students which appear, for this reason, in inverted commas (problem-categories 8, 9, 10, 11 and 12).

The strategically more relevant problem-categories 'general style conventions' and 'genrespecific expressions' were those with the two highest identification-frequencies. They represent, respectively, the textual markers characteristic of different textual genres with the same 
communicative function and the recurrent text segments characteristic of a specific textualgenre and, as such, share a conventionalized character accounting for their generalizability. Their salient frequency and strategic relevance enable, thus, the assumption that question 3 adequately targeted the identification of translation problems.

With regard to the justification of the solutions for translation problems, its frequency for each problem-category is shown in Table 3 in italics. For reasons of space, only the most frequent justification-category for each problem-category is featured in this table also in italics, with its frequency appearing in brackets. This means five different justification-categories, mostly translation strategies, out of the thirteen that result from the students' answers.

The justification-frequency for the solutions of problem-categories, as considered without distinguishing among justification-categories, reveals a clear correlation with its corresponding identification-frequency. Strategically more relevant problem-categories present a higher frequency for the justification of their solutions than strategically less relevant. These, in turn have more frequently justified solutions than those corresponding to translation strategies taken for translation problems. Within strategically more relevant problem-categories, general style conventions' and 'genre-specific expressions' were the two whose solutions were most frequently justified.

As for justification-categories, 'using the conventional equivalent' was both the most frequent and the translationally most relevant. It ranked first not only in the case of two strategically more relevant problems-categories, 'general style conventions' and 'genre-specific expressions', but also in the case of one strategically less relevant problem-category, 'vocabulary'. The most frequent justification-category for the solutions of each of the remaining problem-categories was translationally relevant too, with the exception of the justificationcategory for problems related to syntax, 'thinking of previous solutions for the same problem', which is a metacognitive strategy. On the basis of these results, it can be stated that question 3 adequately helped students to justify the solution for the problems identified leading them to refer to successfully applied translation strategies.

Table 4. Question 4 in the post-translation MQs for module 2

\begin{tabular}{lc}
\hline 4. What have you learnt about the translation of registration conditions? \\
\hline \\
New vocabulary & Text 1 \\
\cline { 2 - 2 } Their typical expressions & 33.5 \\
The need to present their contents clearly & 25 \\
Their macrostructure & 8.3 \\
Their functional markers & 8.3 \\
New information & 8.3 \\
TOTAL & 100
\end{tabular}


4. What recommendation would you give to a peer having to translate this source text or an instance of the textual genre that it belongs to?

\begin{tabular}{lcc}
\hline & Text 2 & Text 3 \\
\cline { 2 - 2 } Consulting parallel texts & 37.5 & 11.8 \\
Not translating literally & 31.3 & 25 \\
Making the text persuasive for the target text-receiver & 6.2 & 52.9 \\
Having a good command of the appropriate vocabulary & & 29.4 \\
Maintaining the author's personal style & & 5.9 \\
Getting background information on the author & & 100 \\
Reading carefully the source text for spotting irony & 100 & \\
TOTAL & & \\
\hline
\end{tabular}

Question 4 was an open-ended question asking trainees what they had learnt about the translation of the source text in question. Its intended aim, though, was to get them to mention the translation strategies that they had used for solving the problems previously identified. This question was meant, thus, as a "double-check" on translation strategies, should these not have been referred to by trainees in answering the 'why' part of question 3. However, the students' answers to this question in the post-translation MQ for text 1 missed such an aim, as the most frequent answer-category was 'new vocabulary'. Though less frequent and translationally more relevant, other answer-categories, such as 'their typical expressions', 'their macrostructure' or 'their functional markers' also had a predominantly declarative character. The only exception was the -more procedural - third most frequent answer-category, i.e., 'the need to present contents clearly'.

This was perceived by the teacher as a more serious deviation from the intended aim than in the case of question 1 in the post-translation MQ for text 1 . Thus, he reworded question 4 already in the post-translation $M Q$ for text 2 , by making its mental action more specific, whereby he replaced 'learning about the translation' with 'giving recommendations for translating'.

Such recommendations were addressed to peers having to translate the same source text or an instance of the textual genre to which it belonged. This - at least potentially - intermental reflection favoured procedural reflection, as students, placed in the "expert" role within a community of apprentices answered question 4 in the post-translation $\mathrm{MQ}$ for text 2 in a way according to the intended aim. They referred in all cases to successfully applied strategies, with the most frequent being also the translationally most relevant ones. In text 2 , the two most numerous were 'consulting parallel texts' and 'not translating literally', both reminiscent of the most frequent justification-category in question 3, i.e. 'using the conventional equivalent'. The third most numerous strategy cited in question 4 , 'making the text persuasive for the target textreceiver', was, in turn, reminiscent of a strategy presented as a problem in question 3 , namely "fulfilling the target text-receiver's expectations".

Given those results, question 4 was left unchanged in the post-translation $\mathrm{MQ}$ for text 3 , whose answers confirmed the successful outcome for text 2 . In text 3 , the three most numerous strategies were 'maintaining the author's personal style', 'getting background 
information on the author' and 'not translating literally'. The first of these did coincide with the justification-category of the same name in question 3 , whilst the last was reminiscent of the justification-category 'using the conventional equivalent' also cited in question 3.

Table 5. Question 5.1 in the post-translation MQs for module 2

\begin{tabular}{lccc}
\hline $\begin{array}{l}\text { 5.1. Having read your translation, some days after completion and } \\
\text { without looking at the source text, did you find it coherent? }\end{array}$ \\
\hline & Text 1 & Text 2 & Text 3 \\
\cline { 2 - 2 } YES & 90.9 & 100 & 100 \\
NO & 9.1 & 0 & 0 \\
TOTAL & 100 & 100 & 100 \\
\hline
\end{tabular}

Table 6. Question 5.2. in the post-translation MQs for module 2

\begin{tabular}{|c|c|c|}
\hline \multicolumn{3}{|c|}{$\begin{array}{l}\text { 5.2. Did you check whether it is comprehensible for another native } \\
\text { speaker? }\end{array}$} \\
\hline & Text 1 & Text 2 \\
\hline YES & 81.8 & 61.6 \\
\hline NO & 18.2 & 38.4 \\
\hline TOTAL & 100 & 100 \\
\hline \multicolumn{3}{|c|}{$\begin{array}{l}\text { 5.2. Did you check whether another Spanish speaking reader could tell } \\
\text { which character in the story utters which opinion? }\end{array}$} \\
\hline \multicolumn{3}{|c|}{ Text 3} \\
\hline YES & \multicolumn{2}{|c|}{83.3} \\
\hline NO & \multicolumn{2}{|c|}{16.7} \\
\hline TOTAL & \multicolumn{2}{|c|}{100} \\
\hline
\end{tabular}

Question 5 consisted of two successive and closely related 'yes-no' questions, 5.1 and 5.2. Each of them pursued the self-evaluation of the translation process from the perspective of the target-text receiver. This meant assessing the application of the bilingual subcompetence, "predominantly procedural knowledge required to communicate in two languages [and comprising] pragmatic, sociolinguistic, textual, grammatical and lexical knowledge" (PACTE 2008: 106).

In the case of question 5.1, trainees were asked to check their translation for coherence, by reading it some time after its completion. Most of them did so in the questionnaire for text 1 and all of them in the post-translation MQ for text 2. Question 5.1 underwent, thus, no change in the post-translation MQ for text 3.

In the case of question 5.2, students were asked to check their translation for comprehensibility, by reading it to another native speaker. Thus, they were expected to engage in intermental reflection, as with question 4 in the post-translation MQs for texts 2 and 3 . The motivational effect of such intermental reflection may explain the considerable percentage of 'yes' answers for question 5.2 in the post-translation MQ for text 1.

This percentage fell considerably in the post-translation MQ for text 2. The possible reason is that two out of the five students answering 'no' misunderstood the term 'native speaker', applying it to German instead of Spanish speaking persons. This term was then removed from 
question 5.2 in the post-translation $M Q$ for text 3. The mental action of this question was also reworded more precisely, by referring the general checking for comprehensibility to a specific, functionally relevant feature of text 3 . This new version of question 5.2 was more frequently answered with 'yes' than its former version in the post-translation MQs for texts 1 and 2. The lower number of 'no' answers also confirmed the greater adequacy of the modified version in targeting the intended aim.

Table 7. Question 6 (question 6.1) in the post-translation MQs for module 2

\begin{tabular}{|c|c|c|c|}
\hline \multicolumn{4}{|c|}{$\begin{array}{l}\text { 6. Have you checked your translation for } \\
\text { sounding" combinations of } \\
\text { a. noun + adjective or prepositional clause } \\
\text { b. verb + noun }\end{array}$} \\
\hline \multicolumn{4}{|c|}{$\begin{array}{l}\text { that can be found in parallel texts, monolingual dictionaries or electronic } \\
\text { corpora? (question } 6.1 \text { in texts } 2 \text { and } 3 \text { ) }\end{array}$} \\
\hline & Text 1 & Text 2 & Text 3 \\
\hline YES & 36.4 & 38.4 & 50 \\
\hline NO & 63.6 & 23.2 & 33.4 \\
\hline NOT ANSWERED & 0 & 38.4 & 16.6 \\
\hline TOTAL & 100 & 100 & 100 \\
\hline
\end{tabular}

Table 8. Question 6.2. in the post-translation MQs for module 2

6.2. Have you checked that the style of your translation sounds appealing for a native speaker and have you asked him/her if s/he finds its contents adequately persuasive? Any relevant comments?

Text 2

YES

69.2

Comments

The text is indeed persuasive

The translation is not fully accomplished

It could be deceitful advertising

No comments

NO

15.4

NOT ANSWERED

15.4

TOTAL

100

69.2

46.2

6.2. Have you read your translation and checked that its style matches the source text's and that the end proves "dramatic" enough? Any relevant comments?

YES

Text 3

91.7

Comments

66.7

Maintaining the author's style results in an "odd-sounding" style but so

was the source text's

The reading aloud has led to changes in the translation

Texts in Spanish related to the source text's topic have been born in

No comments

25

NOT ANSWERED

8.3

TOTAL

$100 \quad 91.7$ 66.7 
Question 6 was also a 'yes-no' question addressing the self-evaluation of the translation process from the perspective of the target text-receiver. Again, such self-evaluation involved assessing the application of the bilingual subcompetence, though in a different way than in question 5. Trainees were now expected to revise their translation for style, checking the results of their intuitions for certain collocational types (such as noun plus adjective) against the sources (such as parallel texts, monolingual dictionaries or electronic corpora), so as to increase their proficiency in the target language.

As the 'no' answers in the post-translation MQ for text 1 considerably surpassed the 'yes' answers, the teacher modified question 6 , adding another question in the post-translation $M Q$ for text 2. From this questionnaire onwards, question 6 actually consisted of question 6.1, corresponding to question 6 as asked in the questionnaire for text 1, and of question 6.2, retargeting the style revision so as to make it more student-motivating.

Drawing on question 5.2, question 6.2 took the form of a 'yes-no' question. It involved not a single mental action, but two, i.e., checking the style with another person and asking him/her about the persuasiveness of the translation. Both actions applied to functionally relevant features of text 2. Question 6.2 also comprised an open-ended question which, bearing on the argumentative character of the 'why' part of question 3, gave the students the opportunity to add any relevant comments. As a result, the frequency of 'yes' answers for question 6.2 in the posttranslation $M Q$ for text 2 was considerably higher than that for question 6.1. in the same questionnaire. Two thirds of the 'yes' answers included comments, with 'yes' answers without comments being half as numerous as those with comments.

In the post-translation $\mathrm{MQ}$ for text 3 , question 6.2 foresaw no explicit interaction with another person, given the minor relevance of the receiver's figure in that text. Trainees were asked to check the style and the "dramatic" effect of their translation simply by reading it aloud, which also adequately led them to meet the intended aim. In the post-translation $M Q$ for text 3 the frequency of the 'yes' answers was considerably higher than in the post-translation MQ for text 2 , whereas the 'not-answered' reduced practically by half and the 'no' answers to zero. The percentage of 'yes' answers which included comments also increased remarkably. So, more modestly, did the percentage of 'yes' answers for question 6.1, a percentage which grew steadily from text 2 onwards, probably as a consequence of introducing question 6.2.

\section{Post-translation MQs for module 5}

The post-translation MQs for module 5 were the result of redesigning the post-translation MQs for module 2 on the basis of the trainees' feedback, as combined with the teacher's insights. This feedback was provided by the students' answers to questions 4 and 5 in the end-module MQ for module 2 (see Tables 9 and 10). Question 4 applied to questions in the post-translation MQs for this module that students would ask themselves automatically in the future. Question 5 had to do with questions worth omitting from future post-translation MQs. 
Table 9. Question 4 in the end-module MQ for module 2

\begin{tabular}{|c|c|c|}
\hline YES & 88.3 & \\
\hline Revision for coherence and comprehensibility (question 5) & & 29.7 \\
\hline Revision for style (question 6) & & 23.5 \\
\hline Problems adequately solved (question 3 ) & & 23.5 \\
\hline Subject of the source text (question 1) & & 5.8 \\
\hline Recommendations for peers (question 4) & & 5.8 \\
\hline NOT ANSWERED & 11.7 & \\
\hline TOTAL & 100 & 88.3 \\
\hline
\end{tabular}

Table 10. Question 5 in the end-module MQ for module 2

\begin{tabular}{|c|c|c|}
\hline \\
\hline \multicolumn{3}{|c|}{$\begin{array}{l}\text { 5. Do you think that certain questions could be omitted from post- } \\
\text { translation questionnaires in the future? Which ones? } \\
\text { YES }\end{array}$} \\
\hline \multicolumn{2}{|c|}{$\begin{array}{ll}\text { YES } & 70.4 \\
\text { Revision for coherence and comprehensibility (question 5) }\end{array}$} & Revision for coherence and comprehensibility (question 5) \\
\hline \multicolumn{2}{|l|}{ Revision for style (question 6) } & 11.7 \\
\hline \multicolumn{2}{|l|}{ Subject of the source text (question 1) } & 11.7 \\
\hline \multicolumn{2}{|l|}{ Information sources (question 2) } & 11.7 \\
\hline \multicolumn{2}{|l|}{ Recommendations for peers (question 4) } & 11.7 \\
\hline & \multicolumn{2}{|l|}{17.9} \\
\hline NOT ANSWERED & \multicolumn{2}{|l|}{11.7} \\
\hline TOTAL & 100 & 70.4 \\
\hline
\end{tabular}

As shown in Table 9 all questions in the post-translation MQs for module 2, apart from question 2 (information sources), were meant to be questions that the students would automatically ask themselves in the future. As for Table 10, all questions in the post-translation MQs for module 2 were regarded as worth omitting from future post-translation MQs, with the exception of question 3 (problems adequately solved).

This question was the only one not to be suppressed from the post-translation MQs for module 2. Simply renumbered as question 1 , it went unchanged into the post-translation MQs for module 5 owing to its proven metacognitive effectiveness. This effectiveness was probably due to the fact that it presented the students with an open task enabling them to self-determine the problems adequately solved and that it asked them to justify the solution for these problems.

The rest of the questions in the post-traslation MQs for module 2 were done without in module 5 , as by the end of module 2 students had regarded them both as dispensable and as already automated. In the case of question 2, the only one whose mental action was not perceived as taken in by the students, the teacher confidently assumed that in module 5 they would resort on their own to information sources, since they had been doing so in carrying out the collaborative translation projects in modules 3 and 4 . 
Only in the case of the revision of the ongoing translation for coherence and comprehensibility, as well as for style respectively targeted by questions 5 and 6 in the posttranslation MQs for module 2, did the teacher not conform to the students' perceptions. Instead, he let prevail the insight that the assessment of the bilingual subcompetence stemming from these two questions was worth maintaining. Thus, he decided to introduce a new question in the post-translation MQs for module 5 retargeting this assessment in a different way than questions 5 and 6 had done. This new question came to be the second in the post-translation MQs for module 5 , after the renumbered question 3.

Table 11. Question 1 in the post-translation MQs for module 5

1. What problems do you think you have adequately solved and why?

\begin{tabular}{|c|c|c|c|c|}
\hline \multirow[t]{2}{*}{ Problem-categories / Justification-categories } & \multicolumn{2}{|c|}{ Identification-frequency } & \multicolumn{2}{|c|}{ Justification-frequency } \\
\hline & T4 & T5 & T4 & T5 \\
\hline 1. General style conventions & 40 & 28.6 & 30 & 28.6 \\
\hline Using the conventional equivalent & & & (30) & $(21.4)$ \\
\hline 2. Cultural references & 30 & 21.4 & 30 & 21.4 \\
\hline $\begin{array}{l}\text { Adding explanations for the target text- } \\
\text { receiver }\end{array}$ & & & (20) & (7.1) \\
\hline 3. Vocabulary & 10 & 35.8 & 10 & 35.8 \\
\hline Using the conventional equivalent & & & & $(28.6)$ \\
\hline Taking the context into account & & & $(10)$ & \\
\hline 4. Syntax & 10 & 7.1 & 20 & 7.1 \\
\hline $\begin{array}{l}\text { Thinking of previous solutions for the same } \\
\text { problem }\end{array}$ & & & (10) & $(7.1)$ \\
\hline 5. Text comprehension & 10 & & & \\
\hline 6. Genre-specific expressions & & 7.1 & & \\
\hline TOTAL/TOTAL & 100 & 100 & 90 & 92.9 \\
\hline
\end{tabular}

As shown in Table 11, 6 categories of identified problems emerged from the students answers to the 'what' part of question 3 in the post-translation MQs for module 5 . These problemcategories were half as many as in module 2 . These problem-categories were half as many as in module 2, despite question 1 in the post-translation MQs for module 5 being actually the unchanged version of question 3 in the post-translation MQs for module 2 . In module 5 , not a single problem-category representing a translation strategy was made out, thus providing evidence of the students' increased capacity to distinguish between actual translation problems and the strategies used for solving them.

As in module 2, more generalizable, strategically more relevant problems (problemcategories 1,2 and 6) were more frequently identified than less generalizable, strategically less relevant problems (problem-categories 3, 4 and 5). 'General style conventions' was again the problem-category most frequently identified. It was followed by 'cultural references', whose strategic relevance lies in the fact that their successful translation involves adapting them to the expectations of the target text-receiver. Hence the adequacy of question 1 (as the unchanged 
version of question 3 in the post-translation MQs for module 2) in addressing the identification of translation problems.

Again, the two most frequently identified problem-categories presented also the highest justification-frequency. Similarly, the most frequent justification-category for each of these two problem-categories, 'using the conventional equivalent' was also translationally the most relevant, exactly coinciding with module 2 .

In module 5 the justification-frequency for all problem-categories considered by texts increased from text $4(90 \%)$ to text $5(92.9 \%)$. In both cases, it came revealingly close to the identification-frequency for each text, $100 \%$. Thus, at the end of module 5 , students justified the solution of practically all problems identified, by referring to successfully applied translation strategies. This confirms that the unchanged version of question 3 also adequately targeted the justification of the solution for the identified translation problems.

With regard to question 2, it retargeted the assessment of the bilingual subcompetence underlying the twofold revision of the target text proposed in questions 5 and 6 in the posttranslation MQs for module 2. The design of question 2 followed primarily that of question 3 , owing to its proven metacognitive effectiveness. This especially applied to the open, autonomyfavouring task proposed in question 2 in the post-translation MQs for module 5. In this task, students were asked to cite changes introduced in their translations, on the basis of having previously read it aloud to themselves or to another person, as well as to justify these changes. Question 2 also built up on its direct precedents, questions 5.2 and 6.2 in the post-translation MQs for module 2, as such justification also involved intermental reflection, thus enhancing its metacognitive effect.

This can be seen in the changes introduced and in their justification. As shown in Table 12, the answer-category 'changes', as opposed to 'no changes', was no fur further differentiated, as concrete examples resisting categorization were mostly cited. Thus, only the identificationfrequency of changes considered as a whole is featured for each text. Conversely, the justification-frequency (in italics) applying to these changes appears differentiated by justification-categories.

Table 12. Question 2 in the post-translation MQs for module 5

\begin{tabular}{|c|c|c|}
\hline $\begin{array}{l}\text { 2. If you have read aloud your } \\
\text { completing it and have introduce }\end{array}$ & $\begin{array}{l}\text { tion to someone else } \\
\text { hanges, which ones anc }\end{array}$ & self some days after \\
\hline CHANGES/Justification-categories & & \\
\hline & Identification-frequency & Justification-frequency \\
\hline CHANGES & 80 & \\
\hline More coherent rendering & & 30 \\
\hline More natural rendering & & 30 \\
\hline NO CHANGES & 10 & \\
\hline NOT ANSWERED & 10 & \\
\hline TOTAL/TOTAL & 100 & 60 \\
\hline
\end{tabular}


2. If you have read aloud your translation to someone else or to yourself some days after completing it and have introduced any changes, which ones and why?

\begin{tabular}{llcc}
\hline CHANGES/Justification-categories & & \multicolumn{2}{c}{ TEXT 4 } \\
\cline { 1 - 1 } CHANGES & & & Jentification-frequency \\
More coherent rendering & 92.3 & 30.7 \\
More natural rendering & & 23.1 \\
Stylistically better rendering & & 23.1 \\
Proposal of a peer & & 7.7 \\
NO CHANGES & 7.7 & \\
TOTAL/TOTAL & 100 & 84.6 \\
\hline
\end{tabular}

In the post-translation $\mathrm{MQ}$ for text $4,80 \%$ of the answers reported changes introduced in the students' translations, whereas $10 \%$ did not and a further $10 \%$ included no response. From this $80 \%, 60 \%$ provided a justification for such changes. In the post-translation MQ for text 5 , up to $92.3 \%$ of the answers referred to changes, probably because question 2 now addressed the genre-specific dialogic structure of the film-script, whereas only $7.7 \%$ of the answers did not. Not a single student left this question unanswered.

In the post-translation MQ for text 5 , the percentage of justified answers changes increased considerably, coming closer to that of changes introduced. This conforms to the behaviour of the justification-frequency considered by texts in question 1 and points to increased translational reasoning in self-evaluating the translation process, possibly as a result of the pedagogical intervention. Such an increase applies not only to questions 1 and 2 in the post-translation MQs for module 5, but also to question 3 in the post-translation MQs for module 2, if we compare the first with the last texts. Finally, as the students' answers to question 2 in the end-module MQ for module 5 reveal (see Table 13), the useful aspects clearly outweighed those needing improvement. These were neither related to the suppressed questions nor to the newly redesigned question 2, thereby implicitly showing the students' agreement with the teacher's redesign of the post-translation MQs for module 5.

Table 13. Question 2 in the end-module $M Q$ for module 5

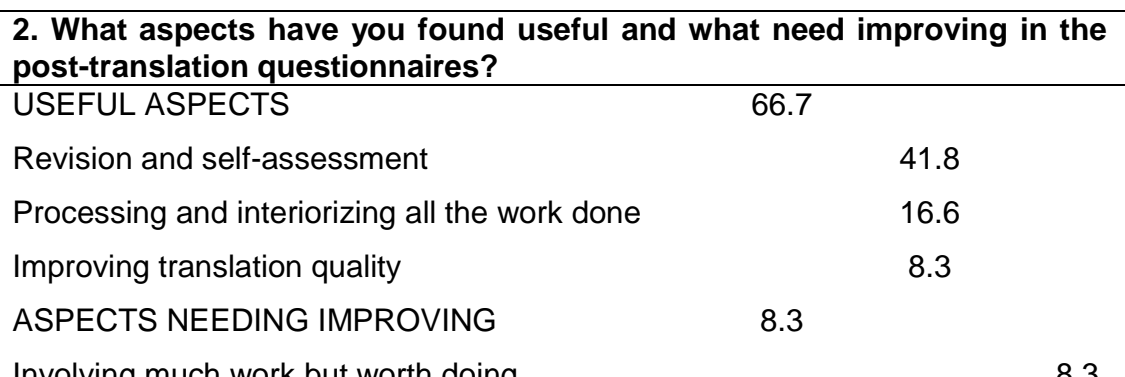




\section{Conclusions}

First we will deal with the three research questions guiding the study and then we will consider its three main findings.

As for the first research question, related to the causes for the perceived inadequacy of the questions redesigned, these causes had always to do with the quality of the mental action involved. They differed, though, according to whether these questions were modified, suppressed or replaced with new ones.

Questions were modified on different grounds, depending on whether they already made part of the post-translation metacognitive questionnaires (MQs) or not. The modification of questions already present in them was quantitatively-based and varied according to the question-type. 'Yes-no' questions were modified when the mental action involved was carried out with less frequency than it was not. Open-ended questions were mostly modified when the mental action expected from the students to meet the intended target was less frequently carried out than other mental actions failing to meet this target. The modification of questions incorporated into the post-translation MQs and subsequently modified was qualitatively-based and had two grounds. Firstly, the mental action involved was so specifically tailored to the particular features of a given text that it could not adequately apply to a new text if not adapted. Secondly, it was sufficiently general so as to be enhanced if reworded according to the particular features of a new text.

Questions in the post-translation MQs for module 2 were suppressed from the posttranslation MQs for module 5 as a consequence of the process of cognitive emancipation undergone by trainees in the course of the pedagogical intervention. The recurrent use of such questionnaires led them to automate and consider not worth performing the mental actions involved.

The causes explaining why questions were replaced by new ones had both a quantitative and a qualitative character: either the mental action involved had been previously carried out with a lower frequency than it had not or it had been taken in, along the way, by the students.

With regard to the second research question, concerning the procedures applying to the ongoing redesign above, they differed depending on whether they applied to modified questions or to questions newly designed.

Procedures applying to modified questions had to do with the rewording of such questions and neatly correlated with the causes explaining their perceived inadequacy. Questions already present in the post-translation MQs were most frequently modified by making the mental action more specific, so as to promote its effect or to make it meet the intended aim. Less frequent, though equally relevant, was the procedure of asking students to consult with another learning 
agent, thereby favouring intermental reflection. Questions incorporated in the post-translation MQs were subsequently modified, by merely readjusting the mental action successfully applied in the first version of such questions to the specific features of the new text.

In the case of newly designed questions, three procedures already successfully applied to the design of previous questions were used. The first consisted in getting students to engage in intermental reflection. The other two were first used in designing the only question experiencing no change from one part of the course to the other and can, thus, be regarded as the most relevant according to student feedback. They consisted in presenting trainees with open, selfdetermined tasks favouring their autonomy as learners and in making them justify their answers, thus leading them to increased translational reasoning.

With regard to the third research question, to do with the effect of the ongoing redesign of post-translation MQs on the trainees' self-evaluation of their translating, it can be stated that such effect was a positive one. With the exception of question 2 in the post-translation MQ for module 2, all other redesigned questions met the originally intended aim better than their previous versions, thereby helping students to address more adequately the subfunctions of such self-evaluation.

This study presents three main findings. The first is the relevance of using instruments for obtaining explicit feedback from students about the redesign of MQs The second is the insight that the metacognitively most significant cause for the perceived inadequacy of a question was the mental action involved not being specific enough to prevent off-target answers. The third is a set of proven metacognitive procedures for (re)designing MQs: getting students to consult other learning agents as a way to promote intermental reflection; referring the mental action involved to an open, autonomy promoting task; and making students account for its outcome.

In our opinion, all these findings have relevant implications for teaching. The use of instruments for obtaining explicit student feedback about the redesign of MQs can prove fruitful both for teachers and trainees alike. Teachers can adjust the pedagogical guidance provided to the evolving needs of trainees and these can come full circle in self-evaluating their translating, by assessing the redesign of instruments that they help to "co-construct". This student-centered redesign process can also benefit from the teacher bearing in mind preventively the metacognitively most significant cause for perceived inadequacies, as well as from him applying procedures for (re)designing MQs validated on the basis of student feedback.

We also believe that these findings represent contributions deserving further research in and through MQs, as used not only in translator and interpreter training but also in other related subjects. Such research could shed light on the relevance of student feedback about the redesign of MQs and highlight possible coincidences and differences in the questions perceived or not as being worth redesigning. It could also verify the validity of the above insight, as well as help to gain more insights into the factors causing questions to be perceived as inadequate. Finally, it could confirm both the metacognitive effectiveness of the three procedures above and whether their (combined) application in open-ended questions targeting students' selfevaluation would promote their strategic awareness. 


\section{References}

Anderson, John Robert. 1990. Cognitive Psychology and its Implications. New York: W.H. Freeman.

Arumí, Marta, and Maria Dolors Cañada. 2005. “Integrating the Metacognitive Dimension to Encourage Autonomous FL Learning: Towards Self-regulation". In Debating Learning Strategies, ed. by Mercedes Díez, Raquel Fernández, and Ana Albach, 223-237. Frankfurt: Peter Lang

Arumí, Marta. 2006. Incidència d'una acció pedagògica dirigida a l'autoregulació, Dos estudis de cas a l'aula d'iniciació a l'aprenentatge de la interpretació consecutiva. Ph.D.dissertation, Universitat Autònoma de Barcelona.

Arumí, Marta. 2009. "Nuevos retos en la formación de intérpretes; la integración del componente metacognitivo en el aula". Trans. Revista de traductología 13: 149-162.

Creswell, John W. 2001. Qualitative Inquire and Research Design. Thousand Oaks: Sage.

Esteve, Olga, and Marta Arumí. 2006. "Using Instruments aimed at self-Regulation in the Consecutive Interpreting Classroom. Two Case Studies". Electronic Journal of Foreign Language Teaching 3 (2):158-189.

Fernández, Francesc, and Patrick Zabalbeascoa. 2012. “Developing Trainee Translators' Strategic Subcompetence through Metacognitive Questionnaires". Meta 57 (3): 740-762.

DOI: 10.7202/1017089ar

Flavell, John. 1979. "Metacognition and Cognitive Monitoring: A New Area of Cognitiv Developmental Inquiry". American Psychologist 34: 906-911.

DOI: $10.1037 / 0003-066 X .34 .10 .906$

Kiraly, Don. 2000. A Social Constructivist Approach to Translator Education; Empowerment. From Theory to Practice. Manchester: St. Jerome Publishing.

Pacte Group. 2008. 'First Results of a Translation Competence Experiment: 'Knowledge of Translation' and 'Efficacy of the Translation Process". In Translator and Interpreter Training. Issues, Methods and Debates, ed. by John Kearns, 104-126. Leeds: Centre for Translation Studies, University of Leeds.

Pozo, J.J., Carles Monereo, and Montserrat Castelló. 2001. "El uso estratégico del conocimiento". In Desarrollo psicológico y educación 2. Psicología de la educación escolar, ed. by César Coll, Jesús Palacios, and Álvaro Marchesi, 211-258. Madrid: Alianza.

Vygotsky, Lev S. 1978. Mind in Society: The Development of Higher Psychological Processes. Cambridge (Mass.): Harvard University Press.

Wenden, Anita. 1999. "An Introduction to Metacognitive Knowldege and Beliefs in Language Learning: Beyond the Basics". System 27: 435-441.

DOI: 10.1016/S0346-251X(99)00043-3 


\section{Appendix}

\section{Pre-translation questionnaire for text 1}

1 Knowing that the sender of the registration conditions that you are going to translate is the German language school Sprachforum München, who do you think that their possible receivers might be?

2 What might the sender intend from the receiver with these registration conditions?

3 If you were the receiver of the target text, how should its style be for it to meet your conventional expectations?

4 What kind of contents can you expect to find in registration conditions and in what logical order. Be as precise as possible.

5 If you happen to know them beforehand, do please cite some fixed phrases in Spanish that could appear in registration conditions originally written in that language?

6 In your opinion, what will be the most relevant problems that you will have to face in translating registration conditions from German into Spanish?

\section{End-module questionnaire for module 2}

1 What have you learnt by collectively answering the questions in the pre-translation questionnaires used in the module?

2 Do you think that you would "automatically" ask yourself in the future any of the questions in the pretranslation questionnaires, even if no such questionnaires needed to be answered? Which ones would they be?

3 What have you learnt in answering the questions in the post-translation questionnaires used in the module?

4 Do you think that you would "automatically" ask yourself in the future any of the questions in the posttranslation questionnaires, even if no such questionnaires needed to be answered? Which ones would they be?

5 Do you think that certain questions could be omitted from post-translation questionnaires in the future? Which ones would they be?

6 Do you think in retrospect that the post-translation questionnaires have helped you to become aware of translation errors? If so, give please one or two examples

\section{End-module questionnaire for module 5}

1 What aspects have you found useful and what need improving in the pre-translation questionnaires?

2 What aspects have you found useful and what need improving in the post-translation questionnaires?

\section{Abstract}

This paper presents a study of the redesign of metacognitive questionnaires carried out along a two-part German-Spanish translation course. The study focuses on post-translation questionnaires used by trainees to self-evaluate their translating, as a function of their strategic subcompetence. Post-translation questionnaires were redesigned ongoingly, as needed, in order to improve their effectiveness in meeting the trainees' evolving needs. This redesign was based on the students' feedback combined with the teacher's perceptions, and led to three types of changes. Firstly, questions not optimally meeting the intended target were modified. As the mental action involved in these questions was not specific enough to prevent off-target answers, each was reworded accordingly and occasionally given an interpersonal 
dimension favouring intermental reflection. Secondly, certain questions were newly designed, so that they included such interpersonal dimension from the very beginning. These also presented the students with open tasks promoting learner autonomy and asked them to justify their answers, thereby enhancing their translational reflection. Thirdly, a group of questions were suppressed from one part of the course to the other, as the mental action involved in each no longer matched the trainees' increased procedural knowledge.

Keywords: trainees' strategic subcompetence, self-evaluation of their translating, metacognitive questionnaires, student-centered redesign

\section{Résumé}

Cet article présente une étude sur le remaniement des questionnaires métacognitifs utilisés dans un cours de traduction allemand-espagnol en deux parties. L'étude se concentre sur les questionnaires posttraduction utilisés par les étudiants pour autoévaluer leur traduction, en tant que fonction de leur souscompétence stratégique. Ces questionnaires post-traduction ont été constamment remaniés pour améliorer leur efficacité, en réponse à l'évolution des besoins des étudiants. Ce remaniement était basé sur le feed-back des étudiants et les perceptions du professeur et a abouti à trois types de changements. Premièrement, des questions qui ne répondaient pas de façon optimale à l'objectif visé ont été modifiées. Étant donné que le mécanisme mental impliqué dans ces questions n'était pas suffisamment spécifique pour éviter des réponses non-ciblées, chacune a été reformulée en conséquence en y intégrant à l'occasion une dimension interpersonnelle favorisant une réflexion intermentale. Deuxièmement, certaines questions ont été reformulées en y incorporant cette dimension interpersonnelle dès le début. Celles-ci présentaient également aux étudiants des tâches ouvertes favorisant l'autonomie de l'apprenant et leur demandaient de justifier leurs réponses, améliorant ainsi leur réflexion traductive. Troisièmement, un groupe de questions a été transféré d'une partie du cours à l'autre, étant donné que le mécanisme mental dans chacune d'elles ne correspondait plus aux connaissances accrues des étudiants dans le domaine du processus.

Mots-clés: sous-compétence stratégique des étudiants, autoévaluation de leur traduction, questionnaires métacognitifs, remaniement centré sur l'étudiant

\section{About the authors}

Dr. Francesc Fernández is junior lecturer at the Department of Translation and Interpreting, Universitat Pompeu Fabra, Barcelona, where he mainly teaches translation and German as a foreign language. His areas of research include translation and foreign language didactics and he is currently conducting a project on the mentoring of translator trainees with the help of former students now working as professional.

Address: Universitat Pompeu Fabra, Departament de Traducció i Ciències del Llenguatge, Facultat de Traducció i Interpretació, Roc Boronat 138, E-08018 Barcelona (Spain)

E-mail: francesc.fernandez@upf.edu

Dra. Marta Arumí is junior lecturer at the Department of Translation and Interpreting, Universitat Autònoma de Barcelona, where she mainly teaches conference interpreting at graduate and undergraduate level. Her areas of research include interpreter didactics, learner autonomy and selfregulation, as well as interpreting for the public services, the object of the MIRAS research group (http://grupsderecerca.uab.cat/miras/es), which she coordinates.

Address: Universitat Autònoma de Barcelona, Facultat de Traducció i d'Interpretació, Plaça del Coneixement. Edifici K-Campus, 08193 Bellaterra (Spain)

E-mail: marta.arumi@uab.cat 